Review

\title{
Reviewing the Effects of L-Leucine Supplementation in the Regulation of Food Intake, Energy Balance, and Glucose Homeostasis
}

\author{
João A.B. Pedroso, Thais T. Zampieri and Jose Donato, Jr. * \\ Department of Physiology and Biophysics, Institute of Biomedical Sciences, University of São Paulo, \\ São Paulo 05508-000, Brazil; E-Mails: nutri.pedroso@gmail.com (J.A.B.P.); \\ thaizampieri@gmail.com (T.T.Z.)
}

* Author to whom correspondence should be addressed; E-Mail: jdonato@icb.usp.br; Tel.: +55-11-3091-0929; Fax: +55-11-3091-7285.

Received: 27 March 2015 / Accepted: 12 May 2015 / Published: 22 May 2015

\begin{abstract}
Leucine is a well-known activator of the mammalian target of rapamycin (mTOR). Because mTOR signaling regulates several aspects of metabolism, the potential of leucine as a dietary supplement for treating obesity and diabetes mellitus has been investigated. The objective of the present review was to summarize and discuss the available evidence regarding the mechanisms and the effects of leucine supplementation on the regulation of food intake, energy balance, and glucose homeostasis. Based on the available evidence, we conclude that although central leucine injection decreases food intake, this effect is not well reproduced when leucine is provided as a dietary supplement. Consequently, no robust evidence indicates that oral leucine supplementation significantly affects food intake, although several studies have shown that leucine supplementation may help to decrease body adiposity in specific conditions. However, more studies are necessary to assess the effects of leucine supplementation in already-obese subjects. Finally, although several studies have found that leucine supplementation improves glucose homeostasis, the underlying mechanisms involved in these potential beneficial effects remain unknown and may be partially dependent on weight loss.
\end{abstract}

Keywords: branched-chain amino acids; obesity; diabetes mellitus; protein synthesis; central nervous system; mTOR 


\section{Introduction}

Several nutrients have nutritional properties that exceed their roles as energy sources or molecule precursors. This is the case for the branched-chain amino acid (BCAA) L-leucine (in this manuscript, we will use the term leucine). Leucine is an essential amino acid for protein synthesis. Additionally, similarly to other amino acids, the carbon skeleton of leucine can be used to generate ATP. However, leucine can also regulate several cellular processes such as protein synthesis, tissue regeneration, and metabolism. Therefore, leucine supplementation has been studied in a variety of conditions such as aging, muscle lesions, protein/energy deprivation, obesity, and diabetes mellitus. Because leucine availability influences signaling pathways involved in the regulation of metabolism and because the incidence of metabolic diseases has reached alarming levels worldwide, investigating nutritional supplements that are potentially beneficial for the treatment and prevention of obesity and diabetes mellitus has become of paramount importance. Thus, the objective of the present review was to summarize and discuss the available evidence regarding the mechanisms and the effects of leucine supplementation in the regulation of food intake, energy balance, and glucose homeostasis.

\section{Intracellular Mechanisms Activated by Leucine}

For decades, amino acids have been known to be important regulators of protein synthesis [1]. Although protein synthesis can be stimulated by several isolated amino acids [2], leucine has a particularly potent effect [3-6]. The initiation of mRNA translation is the major mechanism by which leucine stimulates protein synthesis. Classical studies have shown that the regulation of mRNA translation by leucine is dependent on the mammalian target of rapamycin (mTOR) because rapamycin, a specific mTOR inhibitor, is able to blunt the effects of leucine [4,7-9]. mTOR is a serine/threonine kinase that is involved in the regulation of multiple cellular processes, including protein synthesis and cell growth, proliferation, and survival. mTOR controls protein synthesis through mTOR complex 1 (mTORC1), which comprises mTOR itself and other proteins, as follows: regulatory-associated protein of mTOR (Raptor), mammalian lethal with SEC13 protein 8 (MLST8), proline-rich Akt/PKB substrate $40 \mathrm{kDa}$ (PRAS40), and DEP domain-containing mTOR-interacting protein (DEPTOR) (Figure 1). This protein complex is an important nutrient sensor that is regulated by amino acids (especially by leucine) as well as by growth factors and hormones that are secreted in response to nutrient ingestion (i.e., insulin). mTORC1 has two major mechanisms of activation, via the tuberous sclerosis complex (TSC1/2) and the Rag complex. Hormones such as insulin and insulin growth factor-1 (IGF-1) activate the mTORC1 complex primarily through the TSC complex [10]. However, amino acid-dependent mTORC1 activation occurs through the Rag complex [11] (Figure 1). The presence of amino acids activates Rag GTPase heterodimers, which interact with Raptor. This interaction changes the intracellular localization of mTOR to a compartment that also contains the Ras homolog enriched in brain (Rheb) protein, which leads to mTORC1 complex activation [11]. Recent studies have shown that the enzyme that catalyzes the ligation of leucine to its transfer RNA (tRNA) is responsible for sensing leucine cellular levels and activating the Rag complex [12]. In this regard, leucyl-tRNA synthetase plays a non-canonical role by directly binding to Rag GTPase in an amino acid-dependent manner, and acts as a GTPase-activating protein for Rag GTPase to promote mTORC1 activation [12] 
(Figure 1). Additionally, the cellular uptake of L-glutamine and its subsequent rapid efflux in the presence of essential amino acids (i.e., leucine) represent a rate-limiting step in mTOR activation [13]. Blocking solute carrier family 1 member 5 (SLC1A5), which is a high-affinity L-glutamine transporter, leads to mTORC1 inhibition (Figure 1). mTORC1 activity depends on a bidirectional transporter that regulates the simultaneous efflux of L-glutamine out of cells and the transport of leucine (and other essential amino acids) into cells. This bidirectional amino acid transport is mediated by the heterodimeric, bidirectional antiporter solute carrier family 7 member 5 (SLC7A5)/SLC3A2 [13]. Overall, this system regulates the intracellular concentration of essential amino acids, which is required for Rag-mTORC1 complex activation (Figure 1).

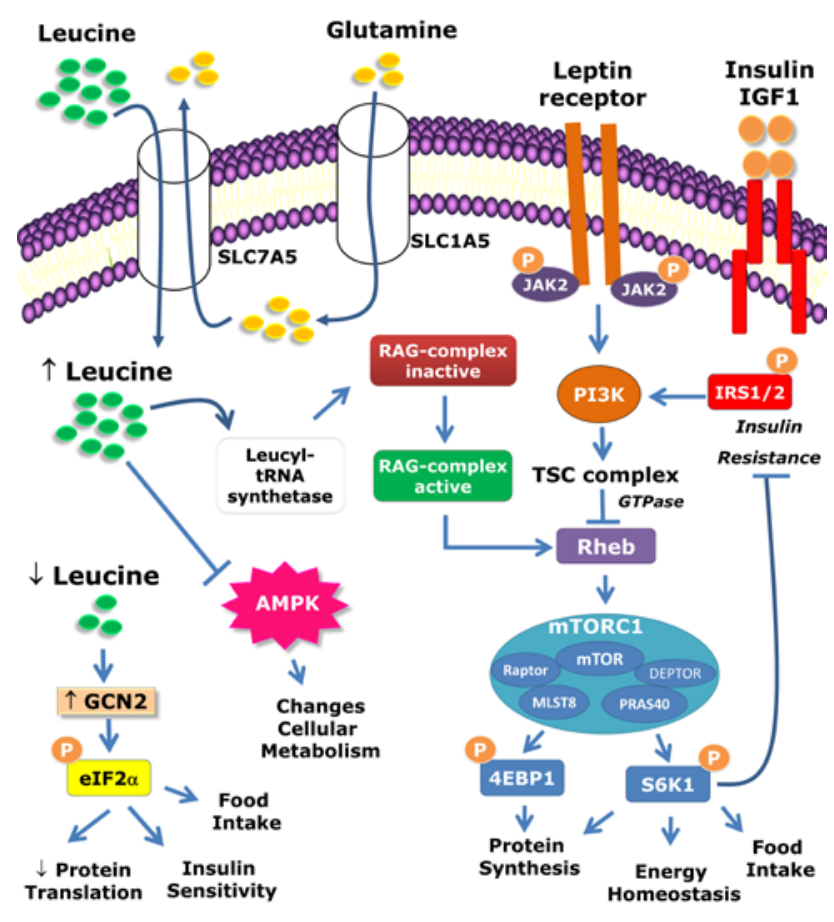

Figure 1. Intracellular mechanisms activated by leucine. The mammalian target of rapamycin complex 1 (mTORC1) comprises mTOR, Raptor, mLST8, PRAS40, and DEPTOR. mTORC1 is activated by amino acids (especially leucine) as well as by hormones such as leptin, insulin, and IGF-1. mTORC1 can be activated by different pathways. Hormonal activation primarily occurs through the TSC complex. However, amino acid-dependent mTORC1 activation occurs through the Rag complex. The leucyl-tRNA synthetase is responsible for sensing leucine cellular levels and activating the Rag complex. The cellular uptake of L-glutamine and its subsequent rapid efflux in the presence of leucine represent the rate-limiting step of mTOR activation. The protein p70-S6 kinase 1 (S6K1) and eukaryotic initiation factor 4E (eIF4E) binding protein 1 (4E-BP1) are key downstream targets of mTORC1. S6K1 also phosphorylates components of the insulin signaling pathway, which may lead to insulin resistance in situations of nutrient abundance such as in obesity. The anorexigenic effects of leptin require both the phosphatidylinositol-4,5-bisphosphate 3-kinase (PI3K) and mTOR/S6K1 signaling pathways. Because mTOR is a downstream target of PI3K signaling, the acute anorexigenic effects of leptin may depend on the $\mathrm{PI} 3 \mathrm{~K} / \mathrm{mTOR} / \mathrm{S6K} 1$ pathway. 
The proteins p70-S6 kinase 1 (S6K1) and eukaryotic initiation factor 4E (eIF4E) binding protein 1 (4E-BP1) are key downstream targets of mTORC1 and are therefore influenced by leucine availability (Figure 1). These proteins, when phosphorylated by mTORC1, lead to mRNA translation initiation and protein synthesis. Although the S6 ribosomal protein is the classical target of S6K1 serine/threonine phosphorylation, S6K1 can also phosphorylate insulin signaling pathway components [14] (Figure 1). This effect is relevant to inducing insulin resistance in situations of nutrient abundance such as in obesity [14,15]. Hypothalamic S6K1 also regulates the energy balance [16]. These topics will be discussed later in this review. Leucine may also signal through other pathways in addition to the mTOR pathway. For example, several studies have indicated that leucine can modify AMP-activated protein kinase (AMPK) activation [17-23]. Leucine-induced modification of AMPK signaling possibly causes changes in cellular metabolism and may mediate some of the effects of leucine. Furthermore, the general control non-depressible kinase 2 (GCN2) pathway is also affected by leucine availability [24]. More specifically, leucine deprivation increases GCN2 signaling, which in turn phosphorylates eukaryotic initiation factor $2 \alpha$ (eIF2 $\alpha$ ). This effect leads to repression of protein translation [25]. The activation of this pathway by changes in leucine levels may alter insulin sensitivity [24]. Hypothalamic eIF2 $\alpha$ signaling also regulates food intake [26].

\section{Leucine-Responsive Tissues}

Previous studies have demonstrated that numerous tissues respond to acute and chronic leucine treatment (Figure 2). For example, oral leucine administration increases protein synthesis in the white adipose tissue, skeletal muscle, liver, heart, kidney, and pancreas [5,7,9,27-30]. In all of these tissues except the kidneys, leucine increases S6K1 and 4E-BP1 phosphorylation, indicating mTOR signaling pathway activation [9,28]. Oral leucine supplementation has also been shown to induce S6K1 phosphorylation in the hypothalamus [31]. Leucine metabolism depends on the first and reversible transamination step, which is catalyzed by the branched-chain amino acid transaminase (BCAT) enzyme (Figure 2). BCAT has two isoforms that are codified by different genes. The cytosolic form of BCAT (BCATc; encoded by the Bcat1 gene) is highly expressed in the brain/peripheral nerves and is nearly absent in other tissues. The mitochondrial form of BCAT (BCATm; encoded by the Bcat2 gene) is expressed in multiple tissues [27,32-34]. Importantly, neither isoform is expressed in the liver or gut, which allows the BCAAs to bypass the portal venous system without being metabolized following their intestinal absorption (Figure 2). This characteristic is unique among amino acids. Therefore, the systemic BCAA levels rise significantly after meals, allowing all of the tissues in the body to sense BCAA intake, whereas other amino acids are highly metabolized by the gut or liver before reaching the systemic circulation (Figure 2). The second and irreversible step in the metabolism of leucine is catalyzed by the branched-chain $\alpha$-ketoacid dehydrogenase complex (BCKDK), which is expressed in numerous tissues. Previous studies have shown that BCAA oxidation is self-regulated. Consequently, increased BCAA levels induce higher BCAT and BCKDK complex activities [35,36]. This mechanism prevents excessive BCAA levels that otherwise could be toxic [37]. Therefore, changes in BCAT and BCKDK complex expression in response to leucine supplementation may represent an alternative way to identify leucine-responsive tissues. Zampieri et al. [31,38] found that chronic leucine supplementation in the drinking water increased BCATc, BCATm, and BCKDK expression in the 
hypothalamus of mice and rats consuming either a regular rodent diet or a high-fat diet (HFD). These results provided additional evidence that the central nervous system (CNS), including the hypothalamus, is also sensitive to changes in leucine intake.

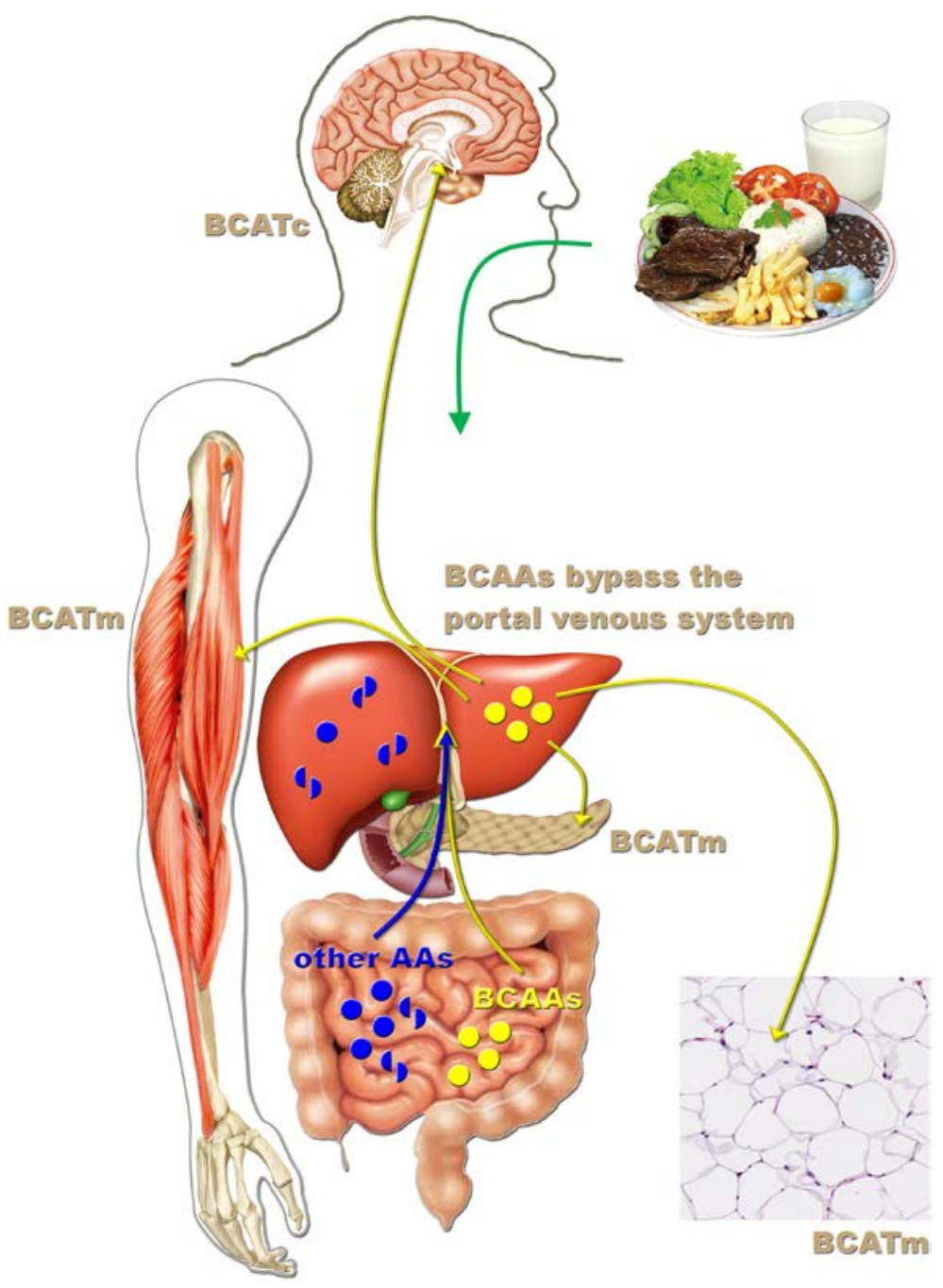

Figure 2. Leucine-responsive tissues. After protein-rich meals, circulating BCAA levels significantly increase, whereas other amino acids are highly metabolized by the gut or liver before reaching the systemic circulation. Branched-chain amino acid transaminase (BCAT) catalyzes the first and reversible transamination step of leucine degradation. This enzyme is not expressed in the liver, which allows the BCAAs to bypass the portal venous system following their intestinal absorption. In the brain, leucine is metabolized by the cytosolic form of BCAT (BCATc), whereas in other tissues (e.g., white adipose tissue, skeletal muscle, and pancreas), the mitochondrial form of BCAT (BCATm) prevails.

\section{Central Effects of Leucine}

The CNS is an important site for regulating food intake, energy balance and glucose homeostasis [39]. Because leucine influences critical cellular processes through mTOR activation, it is important to determine whether this enzyme is expressed in the brain and exerts relevant effects in the nervous system. In this regard, Cota et al. [40] found that although mTOR is ubiquitously distributed in the 
CNS, the phosphorylated form of mTOR at $\operatorname{Ser}^{2448}$ (pmTOR) is more restrictively expressed. pmTOR is highly localized in the hypothalamic nuclei, which are involved in the regulation of energy balance, including the paraventricular nucleus of the hypothalamus (PVH) and the arcuate nucleus of the hypothalamus (ARH). A similar distribution pattern was observed for the activated form of S6K1 (phosphorylated at $\mathrm{Thr}^{389}$, pS6K1). Neurochemically and functionally defined populations of neurons exist in the ARH. Cells closer to the third ventricle co-express neuropeptide Y (NPY), agouti-related peptide (AgRP), and $\gamma$-aminobutyric acid (GABA). These cells stimulate food intake and are therefore inhibited by nutrient ingestion. Another population of cells located more laterally in the ARH co-expresses proopiomelanocortin (POMC) and cocaine- and amphetamine-regulated transcript (CART). These cells promote reduction in food intake and are activated by nutrient ingestion [39]. Approximately $90 \%$ of NPY/AgRP/GABA cells express pmTOR and pS6K1, whereas these phosphorylated proteins are found in 45\% of POMC/CART cells in the ARH [40]. Fasting reduces hypothalamic pS6K1 and pmTOR expression [40]. Interestingly, intracerebroventricular (icv) leucine administration acutely decreases the food intake and body weight of rats, and these effects are blocked by rapamycin [40]. Another study found that changes in hypothalamic S6K1 activity modify the energy homeostasis of rats [16]. Virus-induced S6K1 hyper-activation in the mediobasal hypothalamus (MBH), which includes the ARH and other nuclei, decreased the NPY/AgRP expression, food intake, weight gain, and energy expenditure of rats [16]. Moreover, constitutive S6K1 activation in the MBH increases the acute anorexigenic effects of leptin and protects animals against diet-induced obesity and insulin resistance [16]. Additionally, icv infusion of the anorexigenic hormone leptin increases hypothalamic pS6K1 expression and reduces food intake and body weight in a rapamycin-dependent manner [16,40]. Overall, these results suggest that hypothalamic mTOR/S6K1 signaling regulates food intake and energy balance and mediates the acute anorexigenic effects of leptin. Because previous studies have suggested that the acute anorexigenic effects of leptin are also mediated by PI3K signaling [41,42] and that mTOR is a downstream target of PI3K signaling [10], the acute anorexigenic effects of leptin may depend on the PI3K/mTOR/S6K1 pathway (Figure 1).

Several studies have investigated which neuronal circuitries are required for the central effects of leucine (Figure 3). MBH leucine infusion induces the expression of c-Fos, a marker of neuronal activation, in the PVH and ARH as well as in the nucleus of the solitary tract (NTS), which is a structure located in the caudal brainstem [43] (Figure 3). NTS neurons receive sensory information from the gastrointestinal tract and integrate it with other signals to regulate food intake. The reduction in food intake caused by $\mathrm{MBH}$ leucine infusion is blocked by either a melanocortin receptor or an oxytocin receptor antagonist, suggesting that a neuronal circuitry between the melanocortin system (POMC cells) and PVH oxytocin-reactive neurons is likely required for the central effects of leucine [43]. The direct administration of leucine into the NTS also reduces food intake and body weight, indicating that both extra-hypothalamic (NTS) and hypothalamic (ARH and PVH) sites are involved in the central effects of leucine on feeding [44] (Figure 3). However, other studies have shown that oral leucine administration does not induce c-Fos expression in the PVH, ARH or NTS [31,45]. In one such study, oral leucine administration induced c-Fos expression in the area postrema (AP), which is an important brain structure responsible for detecting toxins and controlling nausea and vomiting [31] (Figure 3). The activation of cells in the AP by leucine may explain why some studies observed taste aversion in animals consuming a leucine-rich diet $[17,46]$. Furthermore, 
orexin-expressing neurons in the lateral hypothalamic area (LHA) are also involved in energy balance regulation and are responsive to amino acids. However, although nonessential amino acids activate orexin-expressing neurons, leucine produces no effects [45] (Figure 3).

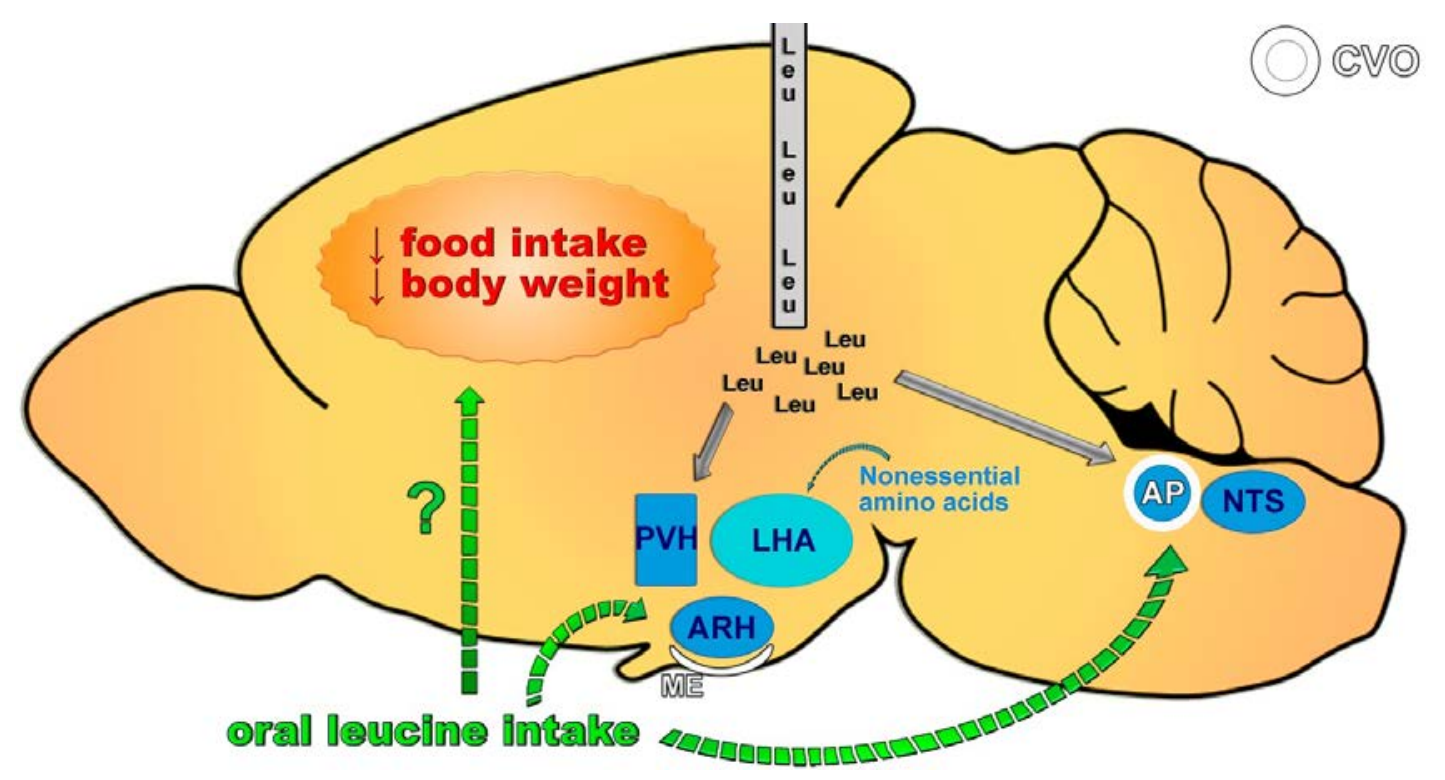

Figure 3. Neuronal circuitries required for the central effects of leucine on feeding. Central leucine administration (intracerebroventricular or parenchymal) acutely decreases food intake and body weight. This response is due to the activation of hypothalamic nuclei involved in regulating energy balance, including the paraventricular nucleus of the hypothalamus (PVH) and the arcuate nucleus of the hypothalamus (ARH), as well as extra-hypothalamic sites such as the nucleus of the solitary tract (NTS). Conversely, oral leucine administration does not induce neuronal activation in the $\mathrm{PVH}, \mathrm{ARH}$, or NTS but does cause c-Fos expression in the area postrema (AP). Consequently, no robust evidence indicates that oral leucine intake affects food intake. CVO, circumventricular organ; ME, median eminence.

\section{Does Leucine Regulate Food Intake?}

As previously mentioned, several studies found that central leucine infusion reduces food intake in rodents $[17,40,43,44,46,47]$. However, the capacity of leucine to modulate food intake is controversial. Many supplementation approaches have been used to study the effects of leucine on food intake, including leucine supplementation in the drinking water, in the diet and through gavage, as well as by subcutaneous (sc), intraperitoneal (ip), and central injections. To clarify whether leucine supplementation is able to influence feeding behavior, we summarized the results from studies that recorded food intake in leucine-supplemented rodents or humans (Tables 1-3). These studies were organized according to the route of leucine supplementation (by central administration, in the diet, or in the drinking water/by other routes). Interestingly, all of the studies evaluating the effects of central leucine infusion observed decreased food intake (Table 1) [17,40,43,44,46,47]. These findings demonstrated that leucine could inhibit food intake by directly affecting the CNS (Figure 3 ). This result is not surprising because it is well known that the brain is able to sense changing nutrient levels 
to regulate the energy balance [43]. However, of 30 studies investigating the effects of leucine supplementation in the diet, two studies found increased food intake in leucine-treated animals [48,49], and only four studies reported decreased food intake in the leucine-supplemented groups [17,46,50,51] (Table 2). From these studies, two observed increased taste aversion to the leucine-rich diet, which may explain the reduction in food intake $[17,46]$. To avoid possible aversive behavior in relation to the diet, several studies supplemented leucine in the drinking water (Table 3). Of 13 studies, two observed that leucine supplementation decreased food intake in specific conditions [52,53]. For example, leucine supplementation in the drinking water decreased the food intake of a polygenic model predisposed to type 2 diabetes (RCS10 mice) but did not affect the food intake of a monogenic model predisposed to obesity and severe insulin resistance (yellow agouti mice) [52]. In another study, leucine supplementation in the drinking water decreased the food intake in males but not in females consuming a regular rodent diet. No effect was observed in mice consuming an HFD [53]. Additionally, one study reported increased food intake in animals supplemented with leucine in the drinking water [54]. No changes in food intake were observed in mice that received leucine supplementation through gavage, ip or sc injections (Table 3). Thus, the central anorexigenic effect of leucine is not well recapitulated when leucine supplementation is provided through an oral form (Figure 3).

Table 1. Summary of the studies that investigated the effects of central leucine treatment on feeding.

\begin{tabular}{ccccc}
\hline Reference & Route & Duration & Comments & Effects on Feeding \\
\hline$[40]$ & icv & Acute & - & Decreased \\
{$[17]$} & icv & Acute & - & Decreased \\
{$[43]$} & MBH & Acute/7 days & Food intake decreased in the first 2 days & Decreased \\
{$[44]$} & NTS & Acute & - & Decreased \\
{$[46]$} & icv & Acute & - & Decreased \\
{$[47]$} & icv & Acute & - & Decreased \\
\hline
\end{tabular}

icv, intracerebroventricular; MBH, mediobasal hypothalamus; NTS, nucleus of the solitary tract.

Table 2. Summary of the studies that investigated the effects of leucine supplementation in the diet on feeding.

\begin{tabular}{ccclc}
\hline Reference & Route & Duration & \multicolumn{1}{c}{ Comments } & Effects on Feeding \\
\hline$[55]$ & Diet & 14 days & Normal and tumor-bearing pregnant rats & No changes \\
\hline$[56]$ & Diet & Acute & Overnight food-deprived adult and old rats & No changes \\
\hline$[57]$ & Diet & 20 days & Normal and tumor-bearing pregnant rats & No changes \\
\hline$[58]$ & Diet & 12 days & Young and tumor-bearing pregnant rats & No changes \\
\hline$[59]$ & Diet & 10 days & Adult and old rats & No changes \\
\hline$[60]$ & Diet & 14 days & Leucine increased nocturnal meal size & No changes \\
\hline$[61]$ & Diet & 9 weeks & Leucine + phenylalanine supplementation & No changes \\
\hline$[62]$ & Diet & 7 days & - & No changes \\
\hline \multirow{2}{*}[17]{} & Diet & \multirow{2}{*}{3 weeks } & $\begin{array}{l}\text { Aversive behavior to leucine-rich diet in the } 1^{\circ}, \\
\text { but not in the } 2^{\circ} \text { and } 21^{\circ} \text { days. }\end{array}$ & Decreased \\
\hline
\end{tabular}


Table 2. Cont.

\begin{tabular}{|c|c|c|c|c|}
\hline Reference & Route & Duration & Comments & $\begin{array}{c}\text { Effects on } \\
\text { Feeding } \\
\end{array}$ \\
\hline [63] & Diet & 12 weeks & $\begin{array}{l}\text { Healthy elderly men. Energy intake and macronutrient } \\
\text { composition were calculated from dietary intake records. }\end{array}$ & No changes \\
\hline [64] & Diet & 8 weeks & Regular and high-fat diets & No changes \\
\hline [65] & Diet & 21 days & Lactating rats & No changes \\
\hline$[66]$ & Diet & 5 weeks & - & No changes \\
\hline$[67]$ & Diet & 24 weeks & $\begin{array}{l}\text { Elderly type } 2 \text { diabetic men; } 3 \text { days' dietary intake records } \\
\text { to evaluate energy and macronutrient intake. }\end{array}$ & No changes \\
\hline [68] & Diet & 6 weeks & Previously obese rats & No changes \\
\hline$[21]$ & Diet & 6 weeks & Regular and high-fat diets & No changes \\
\hline$[50]$ & Diet & 7 days & $\begin{array}{l}\text { HFD-fed mice; leucine produced similar effects as } \\
\text { alanine supplementation. }\end{array}$ & Decreased \\
\hline [51] & Diet & 20 weeks & Mice consuming an HFD & Decreased \\
\hline [69] & Diet & 40 days & Old rats recovering from unilateral hind-limb casting & No changes \\
\hline$[70]$ & Diet & 9 months & Aging rats & No changes \\
\hline$[48]$ & Diet & 6 months & $\begin{array}{l}\text { Increased food intake only in the first } 2 \text { weeks of } \\
\text { supplementation }\end{array}$ & $\begin{array}{l}\text { Increased/ } \\
\text { No changes }\end{array}$ \\
\hline$[71]$ & Diet & 8 weeks & Rats consuming an HFD & No changes \\
\hline [46] & Diet & 4 days & Pronounced taste aversion & Decreased \\
\hline [49] & Diet & 24 weeks & $\begin{array}{l}\text { Leucine increased food intake only in some points } \\
\text { along the experiment }\end{array}$ & $\begin{array}{l}\text { Increased/ } \\
\text { No changes }\end{array}$ \\
\hline$[72]$ & Diet & 2 weeks & Nutritional recovery & No changes \\
\hline [73] & Diet & 40 days & Adult rats recovering from unilateral hind-limb casting & No changes \\
\hline [74] & Diet & 6 weeks & $30 \%$ calorie-restricted diet & No changes \\
\hline [75] & Diet & 27 weeks & - & No changes \\
\hline [47] & Diet & 12 days & - & No changes \\
\hline$[76]$ & Diet & 8 weeks & Non-obese, insulin-resistant rats & No changes \\
\hline
\end{tabular}

Table 3. Summary of the studies that investigated the effects of leucine supplementation in the drinking water or by other routes of feeding.

\begin{tabular}{ccclc}
\hline Reference & Route & Duration & \multicolumn{1}{c}{ Comments } & $\begin{array}{c}\text { Effects on } \\
\text { Feeding }\end{array}$ \\
\hline$[27]$ & Water & 12 days & Leucine or norleucine supplementation & No changes \\
\hline$[54]$ & Water & 14 weeks & $\begin{array}{l}\text { Increased in chow diet group. No change in HFD } \\
\text { group. }\end{array}$ & $\begin{array}{c}\text { Increased/No } \\
\text { changes }\end{array}$ \\
\hline$[77]$ & Water & 14 weeks & Mice consuming an HFD & No changes \\
\hline$[52]$ & Water & 8 weeks & $\begin{array}{l}\text { Food intake decreased in RCS10 mice, but no changes } \\
\text { were observed in yellow agouti mice. }\end{array}$ & $\begin{array}{c}\text { Decreased/No } \\
\text { changes }\end{array}$ \\
\hline$[78]$ & Water & 8 weeks & Mice consuming an HFD & No changes \\
\hline$[79]$ & Water & 10 weeks & Offspring from HFD-fed mothers & No changes \\
\hline$[80]$ & Water & 8 weeks & Supplementation in normal and high-fat diets & No changes \\
\hline$[81]$ & Water & 17 weeks & Mice consuming normal and high-fat diets & No changes \\
\hline$[53]$ & Water & 9 weeks & $\begin{array}{l}\text { Food intake decreased in males, but not females. } \\
\text { No leucine effect in mice fed an HFD. }\end{array}$ & $\begin{array}{c}\text { Decreased/No } \\
\text { changes }\end{array}$ \\
\hline
\end{tabular}


Table 3. Cont.

\begin{tabular}{ccclc}
\hline Reference & Route & Duration & Comments & $\begin{array}{c}\text { Effects on } \\
\text { Feeding }\end{array}$ \\
\hline$[46]$ & Water & 18 days & - & No changes \\
\hline$[31]$ & Water & 6 weeks & $\begin{array}{l}\text { Mice consuming normal and high-fat diets and } \\
\text { ob/ob mice }\end{array}$ & No changes \\
\hline$[38]$ & Water & 6 weeks & Rats consuming normal and high-fat diets & No changes \\
\hline$[82]$ & Water & 21 weeks & Previously obese mice & No changes \\
\hline$[46]$ & Gavage & 3 days & - & No changes \\
\hline$[31]$ & Gavage & 2 days & - & No changes \\
\hline$[83]$ & Gavage & 10 days & Supplementation during skeletal muscle recovery & No changes \\
\hline$[46]$ & ip & 3 days & - & No changes \\
\hline$[46]$ & sc & 3 days & - & No changes \\
\hline
\end{tabular}

ip, intraperitoneal; sc, subcutaneous.

The divergent results caused by oral or central leucine supplementation may be explained by the capacity of leucine to cross the blood-brain barrier (BBB) and reach the CNS. Although a previous study demonstrated that a $4 \%$ leucine-enriched meal could increase the leucine concentration in the cerebrospinal fluid to $44 \%$ [43], whether this change is robust enough to reduce food intake or to persist in the long term remains unknown. In this same study, a high-protein diet did not significantly increase the leucine concentration in the cerebrospinal fluid. Additionally, the changes in leucine levels were approximately seven-fold higher in the plasma than in the cerebrospinal fluid [43]. Therefore, additional studies are warranted to establish the minimum increase in central leucine levels to significantly affect food intake. The BBB and glial cells maintain amino acid concentrations in the CNS parenchyma at well-controlled levels. This is important because several ubiquitous neurotransmitters are amino acids (i.e., glutamate and glycine) or molecules derived from amino acids (i.e., GABA, dopamine, noradrenaline, serotonin, and histamine). Earlier studies have suggested that leucine availability affects the synthesis of amino acid neurotransmitters such as glutamate $[34,84]$. Abrupt changes in amino acid levels in the brain can cause cell death and serious neuronal dysfunction. For example, excessive activation of the N-methyl-D-aspartate (NMDA) receptor, which is a glutamate receptor, causes neuronal death [85]. Similarly, treatment with monosodium glutamate at a young age, when the BBB is not completely formed, causes lesions in several brain areas [86]. Therefore, the ingestion of specific amino acids does not necessarily lead to pronounced changes in their levels in the brain. Likewise, the direct infusion of amino acids into the brain does not necessarily reproduce the physiological effects caused by oral supplementation and therefore may produce supraphysiological effects. Even brain nuclei that are located near circumventricular organs (CVOs) are not free from the BBB influence. For example, the ARH is close to the median eminence (ME), and the NTS is close to the AP (Figure 3). Blood vessels in these areas allow nutrients and hormones to more easily gain access to the CNS. Nonetheless, the BBB and glial cells in these areas remain capable of controlling abrupt changes in the concentration of molecules. Therefore, the available evidence suggests that oral leucine supplementation produces no or very mild effects on food intake (Figure 3). Because previous studies have suggested a role of leucine supplementation in the treatment of 
obesity [87], the practical implication is that if leucine regulates the energy balance and favors a reduced adiposity, this effect is likely not mediated by changes in food intake.

\section{The Effects of Leucine on Body Composition, Obesity, and Energy Expenditure}

Despite the lack of evidence indicating that oral leucine intake affects food intake (Tables 2 and 3), numerous studies have found that leucine supplementation reduces adiposity in specific conditions. For example, leucine supplementation increases body fat loss during a food restriction period [88], decreases the accumulation of fat during aging [70], and partially prevents the development of diet-induced obesity $[17,51,54,71,78,80,81]$. Nonetheless, notably, not all of the studies have found that leucine prevents diet- or age-induced obesity [31,48,77]. The likely weight-reducing effect of leucine is mediated by changes in energy efficiency caused by increased energy expenditure. For example, leucine supplementation increases energy expenditure in mice consuming an HFD [51,54,81] and in genetically obese mice [52]. She et al. [32] provided elegant results indicating that elevated plasma BCAA levels, caused by disruption of the BCATm gene, led to increased oxygen consumption. Consequently, $B C A \mathrm{Tm}^{-1-}$ mice show decreased body weight and adiposity, although these mice also present elevated food intake. Interestingly, changes in locomotor activity, uncoupling protein levels, sympathetic activity, or thyroid hormone levels were not responsible for the increased energy expenditure of $\mathrm{BCATm}^{--}$mice. However, the authors observed an active cycle of increased protein synthesis and degradation. This futile cycle consumes energy, which explains the lean phenotype of $\mathrm{BCATm}^{-/-}$mice $[32,89]$. Therefore, the effects of leucine on energy balance regulation may be primarily caused by the stimulation of protein synthesis, thus highlighting that the peripheral effects of leucine likely prevail over its central action to modifying the energy balance. Moreover, the increased protein synthesis caused by high leucine levels does not necessarily lead to higher protein accretion because the rates of protein synthesis and degradation are finely coupled. This fact is clinically relevant because leucine has been studied as a therapeutic supplement to prevent lean mass and protein loss during aging. Therefore, despite the well-known stimulatory effects of leucine on protein synthesis, leucine supplementation in aging rats [48,70,90] or humans [63,67] apparently did not lead to an increase in lean and protein body mass.

Intriguingly, several studies found no effects on adiposity [52,81,82] or even a predisposition to accumulate more body fat $[38,48,68]$ in animals that began to receive leucine supplementation when they were already obese. A likely explanation for these divergent findings is that mTORC1 activation may promote fat storage in adipocytes by suppressing lipolysis and stimulating de novo lipogenesis [91]. Additionally, mice with disrupted mTORC1 complex exhibit less adipose tissue, suggesting that fat deposition may depend on mTORC1 activity [92]. BCAA supplementation in pregnant rats consuming a protein-restricted diet restored the fat mass of their offspring to levels similar to those of non-restricted animals [93]. Therefore, the weight-reducing effects of leucine supplementation may be counteracted with the direct action of leucine on adipocytes by stimulating adipogenic processes [91,94]. This effect is observed in situations in which the animals are already obese and insulin resistant before receiving leucine supplementation. Additional studies are necessary to determine the molecular mechanisms responsible for these effects. Some authors have suggested a synergism between BCAA and lipids in the development of metabolic dysfunction in multiple 
tissues $[95,96]$. It has been proposed that the increased oxidation of BCAA and fatty acids may lead to mitochondrial stress caused by the abundance of metabolites in the Krebs cycle, which leads to metabolic dysfunctions [95,96].

Leptin is a key hormone involved in the regulation of food intake, energy balance, and glucose homeostasis [39]. Because leucine has direct effects on adipocytes and because leptin synthesis is rapamycin-sensitive, some authors investigated whether leucine could regulate plasma leptin concentrations [97]. These authors observed that increased leucine levels after a meal are partially responsible for inducing the postprandial increase in plasma leptin [97]. If leucine supplementation could increase leptin secretion, this effect may favor weight loss. Nonetheless, obese individuals frequently exhibit hyperleptinemia and leptin resistance [39,98]. Therefore, leucine-mediated leptin secretion may have lower physiological importance in obese individuals. Additionally, obese individuals or rodents already exhibit high circulating BCAA levels [99]. Consequently, leucine/BCAA supplementation may cause lower proportional changes in circulating amino acid levels in obese subjects. Altogether, leucine is unlikely to show beneficial effects as a dietary supplement to help in the treatment of obesity.

\section{Regulation of Glucose Homeostasis by Leucine}

Previous studies observed improved glucose tolerance in leucine-treated animals [51,54,71,78,80-82]. For example, leucine supplementation in the drinking water prevented HFD-induced hyperglycemia and insulin resistance in mice [54]. Although a reduced fat mass may explain a portion of these effects, Eller et al. [71] observed that the improved glucose control occurred independently of changes in body composition. Therefore, leucine supplementation may improve glucose homeostasis and prevent at least part of diet-induced insulin resistance. The underlying mechanisms involved in the effects of leucine on glucose control remain unknown. The pancreas is a potentially important leucine-target tissue that might affect glucose homeostasis. Leucine stimulates protein synthesis in pancreatic $\beta$ and acinar cells through the mTOR signaling pathway [9,100]. Additionally, leucine presents insulinotropic properties [61,81,101-103]. Therefore, increased insulin secretion in leucine-supplemented individuals could improve their postprandial glucose levels. However, some caution when using leucine supplementation in specific situations is recommended. Leucine supplementation in pregnant rats resulted in decreased $\beta$-cell formation in their offspring, which could potentially increase the risk of type 2 diabetes mellitus later in life [104]. Additionally, leucine supplementation enhances tumor growth in a murine model of pancreatic cancer [75].

Other mechanisms, in addition to the regulation of insulin secretion, are likely to be involved in the effects of leucine on glucose control. Several studies have observed that leucine-treated animals exhibited improved insulin sensitivity [54,71,80,81]. Additionally, leucine supplementation decreases glucose-6-phosphatase expression in the livers of mice consuming an HFD, suggesting reduced gluconeogenesis [49,54]. Leucine supplementation increases SIRT1 expression and prevents mitochondrial dysfunction in the livers of diet-induced obese mice [80]. Furthermore, hepatic steatosis and lipid metabolism were improved in leucine-supplemented animals [50,51,54,78,80,105]. BCAA or leucine supplementation also affects glucose metabolism and glycogen synthesis in skeletal muscle $[71,78,80,106]$. Therefore, the direct effects of leucine on insulin-sensitive tissues such as the 
liver and skeletal muscle may influence whole-body glucose homeostasis. Paradoxically, classical studies have found that high physiological BCAA concentrations inhibit the early steps in insulin signaling [4] and that amino acid infusion acutely causes insulin resistance in human skeletal muscle [107]. More recently, some studies revealed that obese and lean humans differ in terms of BCAA metabolism and that BCAA may contribute to insulin resistance in obesity in humans [95,96]. Balage et al. [66] observed that five-week leucine supplementation induced a delay in postprandial stimulation in the early steps of muscle insulin signaling, leading to overall glucose intolerance. Insulin resistance is also induced by mTOR/S6K1 pathway overactivation [108]. Accordingly, the absence of S6K1 protects against age- and diet-induced obesity and enhances insulin sensitivity [15]. Additionally, hyperinsulinemia leads to insulin resistance in the liver and skeletal muscle through a rapamycin-sensitive mechanism [109]. Therefore, excessive mTOR/S6K1 activation by either amino acids or insulin leads to insulin resistance. The mechanism proposed to explain these effects is increased S6K1-mediated phosphorylation of the serine residues of insulin receptor substrate (IRS)-1 [109-111] (Figure 1). Markedly elevated S6K1 activity and increased serine phosphorylation of IRS-1 are observed in animals consuming an HFD or in genetically obese and diabetic models [15,112-114]. Therefore, serine phosphorylation of IRS-1 is considered to be a key feature in insulin resistance.

Because adipose tissue is an important leucine-responsive tissue [28], leucine supplementation may change the secretion pattern of adipokines to a more favorable profile. Previous studies have found that leucine supplementation in previously obese rats increased adiponectin levels [68]. In another study, leucine supplementation reduced inflammatory marker levels in white adipose tissue [78]. Accordingly, a combined leucine and pyridoxine supplementation increased adiponectin levels and reduced the concentrations of oxidative and inflammatory markers in the plasma of obese subjects [115]. Therefore, the improved glucose control in leucine-supplemented animals may be secondary to a more favorable inflammatory profile and cytokine secretion pattern in the adipose tissue. Additionally, increased fat mass due to leucine supplementation may increase glucose uptake by adipocytes, which may help to reduce blood glucose levels in obese animal models [49,82].

The CNS is critically involved in the regulation of glucose homeostasis [116]. Although no clear evidence indicates that oral leucine supplementation is able to affect food intake, the effects of leucine in glucose control may require lower variations in central leucine levels that can be achieved through oral supplementation. Different thresholds that affect food intake and glucose control have been reported in other situations. For example, a low-dose leptin treatment that did not affect the food intake or body weight of leptin-deficient $(o b / o b)$ mice was able to reduce their glucose and insulin levels [117]. Previous studies have observed that leucine depolarizes POMC neurons in vitro [43] and that icv leucine infusion increases hypothalamic POMC expression [17]. Because POMC neurons are critically involved in the regulation of glucose homeostasis and hepatic insulin sensitivity [118], the activation of POMC neurons may be responsible for mediating at least a portion of the anti-diabetic effects of leucine.

Finally, scarce information is available concerning the effects of leucine supplementation on the secretion of gut hormones or on the gut microbiota. Changes in the gut microbiota [119] or gut hormones [120] may produce significant effects in energy and glucose homeostasis regulation. One of the few studies that investigated the effects of leucine on the gut observed that leucine stimulates 
glucagon-like peptide-1 (GLP-1) mRNA levels and secretion [121]. Either GLP-1 or exendin-4, a long-acting GLP-1 agonist, has been shown to enhance glucose tolerance [122,123]. Nonetheless, future studies that directly evaluate these possibilities are required to enhance our understanding of the underlying mechanisms involved in the potential beneficial effects of leucine on glucose homeostasis.

\section{Concluding Remarks}

The potential effects of leucine supplementation are summarized in Figure 4. Because leucine regulates several cellular processes via mTOR and possibly through other signaling pathways, the likely beneficial effects of leucine supplementation have been evaluated in a variety of situations, including as a dietary supplement for the treatment of obesity and diabetes mellitus.

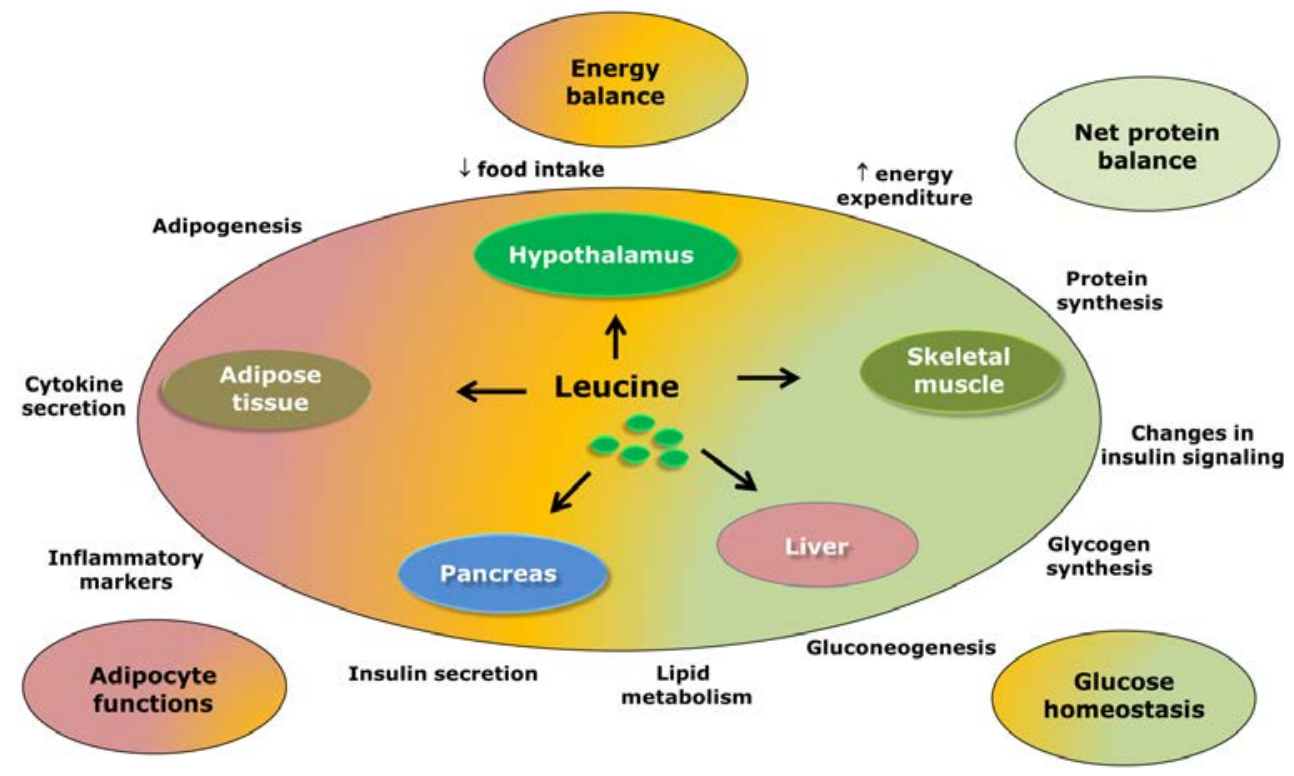

Figure 4. Possible effects of leucine supplementation in the regulation of energy balance and glucose homeostasis. This scheme summarizes the available evidence regarding the likely effects of leucine supplementation in different tissues and its subsequent consequences.

Part of the interest in studying the potential therapeutic application of leucine supplementation emerged from studies observing that leucine could be one of the "active ingredients" in high-protein diets $[17,51,87,124]$. Several studies have found that high-protein diets may be beneficial for weight management and for controlling glucose levels [87,124,125]. However, in the present review, we focused only on studies that directly investigated leucine/BCAA supplementation. Among the practical implications that emerged from the data summarized and discussed in the present review, the first is that no robust evidence indicates that oral leucine supplementation can reduce food intake. Notably, central leucine injection appears to decrease food intake; however, this effect is not well reproduced when leucine is provided as a dietary supplement, which calls its therapeutic application into question. Additionally, several studies indicated that leucine supplementation may help to decrease body adiposity in specific conditions. However, additional studies are warranted to assess the effects of leucine supplementation in already-obese subjects. The studies that initiated leucine supplementation in already-obese animals found no beneficial effects of leucine or even found worsening of the degree of 
adiposity. Therefore, based on the presented data, leucine supplementation is not likely to be helpful as a dietary supplement for treating obesity. Finally, we discussed the potential therapeutic effects of leucine in improving glucose homeostasis. Although some studies have found that leucine supplementation improves glucose tolerance, the underlying mechanisms involved in these effects remain unknown and may be partially dependent on weight loss.

\section{Acknowledgments}

We thank the São Paulo Research Foundation (FAPESP-Brazil) for grant 10/18086-0 and fellowships 12/15517-6 and 13/25032-2.

\section{Author Contributions}

Conceived the manuscript: Jose Donato, Jr. Prepared the figures: João A. B. Pedroso and Thais T. Zampieri. Wrote and revised the manuscript: João A. B. Pedroso, Thais T. Zampieri. and Jose Donato, Jr.

\section{Conflicts of Interest}

The authors declare no conflict of interest.

\section{References}

1. Garlick, P.J. The role of leucine in the regulation of protein metabolism. J. Nutr. 2005, 135, 1553S-1556S.

2. Kimball, S.R.; Jefferson, L.S. Control of translation initiation through integration of signals generated by hormones, nutrients, and exercise. J. Biol. Chem. 2010, 285, 29027-29032.

3. Hong, S.O.; Layman, D.K. Effects of leucine on in vitro protein synthesis and degradation in rat skeletal muscles. J. Nutr. 1984, 114, 1204-1212.

4. Patti, M.E.; Brambilla, E.; Luzi, L.; Landaker, E.J.; Kahn, C.R. Bidirectional modulation of insulin action by amino acids. J. Clin. Investig. 1998, 101, 1519-1529.

5. Anthony, J.C.; Anthony, T.G.; Kimball, S.R.; Vary, T.C.; Jefferson, L.S. Orally administered leucine stimulates protein synthesis in skeletal muscle of postabsorptive rats in association with increased eif4f formation. J. Nutr. 2000, 130, 139-145.

6. Anthony, J.C.; Anthony, T.G.; Layman, D.K. Leucine supplementation enhances skeletal muscle recovery in rats following exercise. J. Nutr. 1999, 129, 1102-1106.

7. Kimball, S.R.; Shantz, L.M.; Horetsky, R.L.; Jefferson, L.S. Leucine regulates translation of specific mrnas in 16 myoblasts through mtor-mediated changes in availability of eif4e and phosphorylation of ribosomal protein s6. J. Biol. Chem. 1999, 274, 11647-11652.

8. Anthony, J.C.; Yoshizawa, F.; Anthony, T.G.; Vary, T.C.; Jefferson, L.S.; Kimball, S.R. Leucine stimulates translation initiation in skeletal muscle of postabsorptive rats via a rapamycinsensitive pathway. J. Nutr. 2000, 130, 2413-2419. 
9. Xu, G.; Kwon, G.; Marshall, C.A.; Lin, T.A.; Lawrence, J.C., Jr.; McDaniel, M.L. Branchedchain amino acids are essential in the regulation of phas-i and p70 s6 kinase by pancreatic betacells. A possible role in protein translation and mitogenic signaling. J. Biol. Chem. 1998, 273, 28178-28184.

10. Mendoza, M.C.; Er, E.E.; Blenis, J. The ras-erk and pi3k-mtor pathways: Cross-talk and compensation. Trends Biochem. Sci. 2011, 36, 320-328.

11. Sancak, Y.; Peterson, T.R.; Shaul, Y.D.; Lindquist, R.A.; Thoreen, C.C.; Bar-Peled, L.; Sabatini, D.M. The rag gtpases bind raptor and mediate amino acid signaling to mtorc1. Science 2008, 320, 1496-1501.

12. Han, J.M.; Jeong, S.J.; Park, M.C.; Kim, G.; Kwon, N.H.; Kim, H.K.; Ha, S.H.; Ryu, S.H.; Kim, S. Leucyl-trna synthetase is an intracellular leucine sensor for the mtorc1-signaling pathway. Cell 2012, 149, 410-424.

13. Nicklin, P.; Bergman, P.; Zhang, B.; Triantafellow, E.; Wang, H.; Nyfeler, B.; Yang, H.; Hild, M.; Kung, C.; Wilson, C.; et al. Bidirectional transport of amino acids regulates mtor and autophagy. Cell 2009, 136, 521-534.

14. Tremblay, F.; Brule, S.; Hee Um, S.; Li, Y.; Masuda, K.; Roden, M.; Sun, X.J.; Krebs, M.; Polakiewicz, R.D.; Thomas, G.; et al. Identification of irs-1 ser-1101 as a target of s6k1 in nutrient- and obesity-induced insulin resistance. Proc. Natl. Acad. Sci. USA 2007, 104, 14056-14061.

15. Um, S.H.; Frigerio, F.; Watanabe, M.; Picard, F.; Joaquin, M.; Sticker, M.; Fumagalli, S.; Allegrini, P.R.; Kozma, S.C.; Auwerx, J.; et al. Absence of s6k1 protects against age- and diet-induced obesity while enhancing insulin sensitivity. Nature 2004, 431, 200-205.

16. Blouet, C.; Ono, H.; Schwartz, G.J. Mediobasal hypothalamic p70 s6 kinase 1 modulates the control of energy homeostasis. Cell Metab. 2008, 8, 459-467.

17. Ropelle, E.R.; Pauli, J.R.; Fernandes, M.F.; Rocco, S.A.; Marin, R.M.; Morari, J.; Souza, K.K.; Dias, M.M.; Gomes-Marcondes, M.C.; Gontijo, J.A.; et al. A central role for neuronal amp-activated protein kinase (ampk) and mammalian target of rapamycin (mtor) in high-protein diet-induced weight loss. Diabetes 2008, 57, 594-605.

18. Fu, L.; Bruckbauer, A.; Li, F.; Cao, Q.; Cui, X.; Wu, R.; Shi, H.; Zemel, M.B.; Xue, B. Leucine amplifies the effects of metformin on insulin sensitivity and glycemic control in diet-induced obese mice. Metabolism 2015, in press.

19. Liang, C.; Curry, B.J.; Brown, P.L.; Zemel, M.B. Leucine modulates mitochondrial biogenesis and sirt1-ampk signaling in c2c12 myotubes. J. Nutr. Metab. 2014, 2014, 239750.

20. Bruckbauer, A.; Zemel, M.B. Synergistic effects of polyphenols and methylxanthines with leucine on ampk/sirtuin-mediated metabolism in muscle cells and adipocytes. PLoS ONE 2014, 9, e89166.

21. Bruckbauer, A.; Zemel, M.B.; Thorpe, T.; Akula, M.R.; Stuckey, A.C.; Osborne, D.; Martin, E.B.; Kennel, S.; Wall, J.S. Synergistic effects of leucine and resveratrol on insulin sensitivity and fat metabolism in adipocytes and mice. Nutr. Metab. (Lond.) 2012, 9, 77. 
22. Wilson, G.J.; Layman, D.K.; Moulton, C.J.; Norton, L.E.; Anthony, T.G.; Proud, C.G.; Rupassara, S.I.; Garlick, P.J. Leucine or carbohydrate supplementation reduces ampk and eef2 phosphorylation and extends postprandial muscle protein synthesis in rats. Am. J. Physiol. Endocrinol. Metab. 2011, 301, E1236-E1242.

23. Xiao, F.; Huang, Z.; Li, H.; Yu, J.; Wang, C.; Chen, S.; Meng, Q.; Cheng, Y.; Gao, X.; Li, J.; et al. Leucine deprivation increases hepatic insulin sensitivity via gcn $2 / \mathrm{mtor} / \mathrm{s} 6 \mathrm{k} 1$ and ampk pathways. Diabetes 2011, 60, 746-756.

24. Zhang, P.; McGrath, B.C.; Reinert, J.; Olsen, D.S.; Lei, L.; Gill, S.; Wek, S.A.; Vattem, K.M.; Wek, R.C.; Kimball, S.R.; et al. The gcn2 eif2alpha kinase is required for adaptation to amino acid deprivation in mice. Mol. Cell. Biol. 2002, 22, 6681-6688.

25. Gallinetti, J.; Harputlugil, E.; Mitchell, J.R. Amino acid sensing in dietary-restriction-mediated longevity: Roles of signal-transducing kinases gen2 and tor. Biochem. J. 2013, 449, 1-10.

26. Maurin, A.C.; Benani, A.; Lorsignol, A.; Brenachot, X.; Parry, L.; Carraro, V.; Guissard, C.; Averous, J.; Jousse, C.; Bruhat, A.; et al. Hypothalamic eif2alpha signaling regulates food intake. Cell Rep. 2014, 6, 438-444.

27. Lynch, C.J.; Hutson, S.M.; Patson, B.J.; Vaval, A.; Vary, T.C. Tissue-specific effects of chronic dietary leucine and norleucine supplementation on protein synthesis in rats. Am. J. Physiol. Endocrinol. Metab. 2002, 283, E824-E835.

28. Lynch, C.J.; Patson, B.J.; Anthony, J.; Vaval, A.; Jefferson, L.S.; Vary, T.C. Leucine is a direct-acting nutrient signal that regulates protein synthesis in adipose tissue. Am. J. Physiol. Endocrinol. Metab. 2002, 283, E503-E513.

29. Anthony, T.G.; Anthony, J.C.; Yoshizawa, F.; Kimball, S.R.; Jefferson, L.S. Oral administration of leucine stimulates ribosomal protein mrna translation but not global rates of protein synthesis in the liver of rats. $J$. Nutr. 2001, 131, 1171-1176.

30. Ijichi, C.; Matsumura, T.; Tsuji, T.; Eto, Y. Branched-chain amino acids promote albumin synthesis in rat primary hepatocytes through the mtor signal transduction system. Biochem. Biophs. Res. 2003, 303, 59-64.

31. Zampieri, T.T.; Pedroso, J.A.; Furigo, I.C.; Tirapegui, J.; Donato, J., Jr. Oral leucine supplementation is sensed by the brain but neither reduces food intake nor induces an anorectic pattern of gene expression in the hypothalamus. PLOS ONE 2013, 8, e84094.

32. She, P.; Reid, T.M.; Bronson, S.K.; Vary, T.C.; Hajnal, A.; Lynch, C.J.; Hutson, S.M. Disruption of bcatm in mice leads to increased energy expenditure associated with the activation of a futile protein turnover cycle. Cell Metab. 2007, 6, 181-194.

33. Sweatt, A.J.; Wood, M.; Suryawan, A.; Wallin, R.; Willingham, M.C.; Hutson, S.M. Branched-chain amino acid catabolism: Unique segregation of pathway enzymes in organ systems and peripheral nerves. Am. J. Physiol. Endocrinol. Metab. 2004, 286, E64-E76.

34. Garcia-Espinosa, M.A.; Wallin, R.; Hutson, S.M.; Sweatt, A.J. Widespread neuronal expression of branched-chain aminotransferase in the cns: Implications for leucine/glutamate metabolism and for signaling by amino acids. J. Neurochem. 2007, 100, 1458-1468.

35. Paxton, R.; Harris, R.A. Regulation of branched-chain alpha-ketoacid dehydrogenase kinase. Arch. Biochem. Biophys. 1984, 231, 48-57. 
36. Harris, R.A.; Joshi, M.; Jeoung, N.H. Mechanisms responsible for regulation of branched-chain amino acid catabolism. Biochem. Biophys. Res. Commun. 2004, 313, 391-396.

37. Imamura, W.; Yoshimura, R.; Takai, M.; Yamamura, J.; Kanamoto, R.; Kato, H. Adverse effects of excessive leucine intake depend on dietary protein intake: A transcriptomic analysis to identify useful biomarkers. J. Nutr. Sci. Vitaminol. 2013, 59, 45-55.

38. Zampieri, T.T.; Torres-Leal, F.L.; Campana, A.B.; Lima, F.B.; Donato, J., Jr. L-leucine supplementation worsens the adiposity of already obese rats by promoting a hypothalamic pattern of gene expression that favors fat accumulation. Nutrients 2014, 6, 1364-1373.

39. Morton, G.J.; Meek, T.H.; Schwartz, M.W. Neurobiology of food intake in health and disease. Nat. Rev. Neurosci. 2014, 15, 367-378.

40. Cota, D.; Proulx, K.; Smith, K.A.; Kozma, S.C.; Thomas, G.; Woods, S.C.; Seeley, R.J. Hypothalamic mtor signaling regulates food intake. Science 2006, 312, 927-930.

41. Donato, J., Jr.; Frazão, R.; Elias, C.F. The pi3k signaling pathway mediates the biological effects of leptin. Arq. Bras. Endocrinol. Metabol. 2010, 54, 591-602.

42. Niswender, K.D.; Morton, G.J.; Stearns, W.H.; Rhodes, C.J.; Myers, M.G., Jr.; Schwartz, M.W. Intracellular signalling. Key enzyme in leptin-induced anorexia. Nature 2001, 413, 794-795.

43. Blouet, C.; Jo, Y.H.; Li, X.; Schwartz, G.J. Mediobasal hypothalamic leucine sensing regulates food intake through activation of a hypothalamus-brainstem circuit. J. Neurosci. 2009, 29, 8302-8311.

44. Blouet, C.; Schwartz, G.J. Brainstem nutrient sensing in the nucleus of the solitary tract inhibits feeding. Cell Metab. 2012, 16, 579-587.

45. Karnani-Mahesh, M.; Apergis-Schoute, J.; Adamantidis, A.; Jensen, L.T.; de Lecea, L.; Fugger, L.; Burdakov, D. Activation of central orexin/hypocretin neurons by dietary amino acids. Neuron 2011, 72, 616-629.

46. Koch, C.E.; Goddeke, S.; Kruger, M.; Tups, A. Effect of central and peripheral leucine on energy metabolism in the djungarian hamster (phodopus sungorus). J. Comp. Physiol. B Biochem. Syst. Environ. Physiol. 2013, 183, 261-268.

47. Laeger, T.; Reed, S.D.; Henagan, T.M.; Fernandez, D.H.; Taghavi, M.; Addington, A.; Munzberg, H.; Martin, R.J.; Hutson, S.M.; Morrison, C.D. Leucine acts in the brain to suppress food intake but does not function as a physiological signal of low dietary protein. Am. J. Physiol. Regul. Integr. Comp. Physiol. 2014, 307, R310-R320.

48. Zeanandin, G.; Balage, M.; Schneider, S.M.; Dupont, J.; Hebuterne, X.; Mothe-Satney, I.; Dardevet, D. Differential effect of long-term leucine supplementation on skeletal muscle and adipose tissue in old rats: An insulin signaling pathway approach. Age 2012, 34, 371-387.

49. Li, X.; Wang, X.; Liu, R.; Ma, Y.; Guo, H.; Hao, L.; Yao, P.; Liu, L.; Sun, X.; He, K.; et al. Chronic leucine supplementation increases body weight and insulin sensitivity in rats on high-fat diet likely by promoting insulin signaling in insulin-target tissues. Mol. Nutr. Food Res. 2013, 57, 1067-1079.

50. Freudenberg, A.; Petzke, K.J.; Klaus, S. Dietary l: -leucine and l: -alanine supplementation have similar acute effects in the prevention of high-fat diet-induced obesity. Amino Acids 2012, 44, 519-528. 
51. Freudenberg, A.; Petzke, K.J.; Klaus, S. Comparison of high-protein diets and leucine supplementation in the prevention of metabolic syndrome and related disorders in mice. J. Nutr. Biochem. 2012, 23, 1524-1530.

52. Guo, K.; Yu, Y.H.; Hou, J.; Zhang, Y. Chronic leucine supplementation improves glycemic control in etiologically distinct mouse models of obesity and diabetes mellitus. Nutr. Metab. (Lond.) 2010, 7, 57.

53. Drgonova, J.; Jacobsson, J.A.; Han, J.C.; Yanovski, J.A.; Fredriksson, R.; Marcus, C.; Schioth, H.B.; Uhl, G.R. Involvement of the neutral amino acid transporter slc6a15 and leucine in obesity-related phenotypes. PLoS ONE 2013, 8, e68245.

54. Zhang, Y.; Guo, K.; LeBlanc, R.E.; Loh, D.; Schwartz, G.J.; Yu, Y.H. Increasing dietary leucine intake reduces diet-induced obesity and improves glucose and cholesterol metabolism in mice via multimechanisms. Diabetes 2007, 56, 1647-1654.

55. Ventrucci, G.; Mello, M.A.; Gomes-Marcondes, M.C. Effect of a leucine-supplemented diet on body composition changes in pregnant rats bearing walker 256 tumor. Braz. J. Med. Biol. Res. 2001, 34, 333-338.

56. Dardevet, D.; Sornet, C.; Bayle, G.; Prugnaud, J.; Pouyet, C.; Grizard, J. Postprandial stimulation of muscle protein synthesis in old rats can be restored by a leucine-supplemented meal. J. Nutr. 2002, 132, 95-100.

57. Ventrucci, G.; de Mello, M.A.; Gomes-Marcondes, M.C. Effects of leucine supplemented diet on intestinal absorption in tumor bearing pregnant rats. BMC Cancer 2002, $2,7$.

58. Gomes-Marcondes, M.C.; Ventrucci, G.; Toledo, M.T.; Cury, L.; Cooper, J.C. A leucine-supplemented diet improved protein content of skeletal muscle in young tumor-bearing rats. Braz. J. Med. Biol. Res. 2003, 36, 1589-1594.

59. Rieu, I.; Sornet, C.; Bayle, G.; Prugnaud, J.; Pouyet, C.; Balage, M.; Papet, I.; Grizard, J.; Dardevet, D. Leucine-supplemented meal feeding for ten days beneficially affects postprandial muscle protein synthesis in old rats. J. Nutr. 2003, 133, 1198-1205.

60. Bassil, M.S.; Hwalla, N.; Obeid, O.A. Meal pattern of male rats maintained on histidine-, leucine-, or tyrosine-supplemented diet. Obesity (Silver Spring) 2007, 15, 616-623.

61. Donato, J., Jr.; Pedrosa, R.G.; de Araujo, J.A., Jr.; Pires, I.S.; Tirapegui, J. Effects of leucine and phenylalanine supplementation during intermittent periods of food restriction and refeeding in adult rats. Life Sci. 2007, 81, 31-39.

62. Zhong, B.; Sakai, S.; Saeki, T.; Kanamoto, R. Excess leucine intake induces serine dehydratase in rat liver. Biosc. Biotechnol. Biochem. 2007, 71, 2614-2617.

63. Verhoeven, S.; Vanschoonbeek, K.; Verdijk, L.B.; Koopman, R.; Wodzig, W.K.; Dendale, P.; van Loon, L.J. Long-term leucine supplementation does not increase muscle mass or strength in healthy elderly men. Am. J. Clin. Nutr. 2009, 89, 1468-1475.

64. Bong, H.Y.; Kim, J.Y.; Jeong, H.I.; Moon, M.S.; Kim, J.; Kwon, O. Effects of corn gluten hydrolyzates, branched chain amino acids, and leucine on body weight reduction in obese rats induced by a high fat diet. Nutr. Res. Pract. 2010, 4, 106-113.

65. López, N.; Sánchez, J.; Picó, C.; Palou, A.; Serra, F. Dietary l-leucine supplementation of lactating rats results in a tendency to increase lean/fat ratio associated to lower orexigenic neuropeptide expression in hypothalamus. Peptides 2010, 31, 1361-1367. 
66. Balage, M.; Dupont, J.; Mothe-Satney, I.; Tesseraud, S.; Mosoni, L.; Dardevet, D. Leucine supplementation in rats induced a delay in muscle ir/pi3k signaling pathway associated with overall impaired glucose tolerance. J. Nutr. Biochem. 2011, 22, 219-226.

67. Leenders, M.; Verdijk, L.B.; van der Hoeven, L.; van Kranenburg, J.; Hartgens, F.; Wodzig, W.K.; Saris, W.H.; van Loon, L.J. Prolonged leucine supplementation does not augment muscle mass or affect glycemic control in elderly type 2 diabetic men. J. Nutr. 2011, 141, 1070-1076.

68. Torres-Leal, F.L.; Fonseca-Alaniz, M.H.; Teodoro, G.F.; de Capitani, M.D.; Vianna, D.; Pantaleao, L.C.; Matos-Neto, E.M.; Rogero, M.M.; Donato, J., Jr.; Tirapegui, J. Leucine supplementation improves adiponectin and total cholesterol concentrations despite the lack of changes in adiposity or glucose homeostasis in rats previously exposed to a high-fat diet. Nutr. Metab. (Lond.) 2011, 8, 62.

69. Magne, H.; Savary-Auzeloux, I.; Migne, C.; Peyron, M.A.; Combaret, L.; Remond, D.; Dardevet, D. Contrarily to whey and high protein diets, dietary free leucine supplementation cannot reverse the lack of recovery of muscle mass after prolonged immobilization during ageing.

J. Physiol. 2012, 590, 2035-2049.

70. Vianna, D.; Resende, G.F.; Torres-Leal, F.L.; Pantaleao, L.C.; Donato, J., Jr.; Tirapegui, J. Long-term leucine supplementation reduces fat mass gain without changing body protein status of aging rats. Nutrition 2012, 28, 182-189.

71. Eller, L.K.; Saha, D.C.; Shearer, J.; Reimer, R.A. Dietary leucine improves whole-body insulin sensitivity independent of body fat in diet-induced obese sprague-dawley rats. J. Nutr. Biochem. 2013, 24, 1285-1294.

72. Pedrosa, R.G.; Donato, J., Jr.; Pires, I.S.; Tirapegui, J. Leucine supplementation increases serum insulin-like growth factor 1 concentration and liver protein/rna ratio in rats after a period of nutritional recovery. Appl. Physiol. Nutr. Metab. 2013, 38, 694-697.

73. Savary-Auzeloux, I.; Magne, H.; Migne, C.; Oberli, M.; Breuille, D.; Faure, M.; Vidal, K.; Perrot, M.; Remond, D.; Combaret, L.; et al. A dietary supplementation with leucine and antioxidants is capable to accelerate muscle mass recovery after immobilization in adult rats. PLOS ONE 2013, 8, e81495.

74. Pedroso, J.A.; Nishimura, L.S.; de Matos-Neto, E.M.; Donato, J., Jr.; Tirapegui, J. Leucine improves protein nutritional status and regulates hepatic lipid metabolism in calorie-restricted rats. Cell Biochem. Funct. 2014, 32, 326-332.

75. Liu, K.A.; Lashinger, L.M.; Rasmussen, A.J.; Hursting, S.D. Leucine supplementation differentially enhances pancreatic cancer growth in lean and overweight mice. Cancer Metab. 2014, 2, 6.

76. Tong, X.; Li, W.; Xu, J.Y.; Han, S.; Qin, L.Q. Effects of whey protein and leucine supplementation on insulin resistance in non-obese insulin-resistant model rats. Nutrition 2014, 30, 1076-1080.

77. Nairizi, A.; She, P.; Vary, T.C.; Lynch, C.J. Leucine supplementation of drinking water does not alter susceptibility to diet-induced obesity in mice. J. Nutr. 2009, 139, 715-719. 
78. Macotela, Y.; Emanuelli, B.; Bång, A.M.; Espinoza, D.O.; Boucher, J.; Beebe, K.; Gall, W.; Kahn, C.R. Dietary leucine-an environmental modifier of insulin resistance acting on multiple levels of metabolism. PLoS ONE 2011, 6, e21187.

79. Chen, H.; Simar, D.; Ting, J.H.; Erkelens, J.R.; Morris, M.J. Leucine improves glucose and lipid status in offspring from obese dams, dependent on diet type, but not caloric intake. J. Neuroendocrinol. 2012, 24, 1356-1364.

80. Li, H.; Xu, M.; Lee, J.; He, C.; Xie, Z. Leucine supplementation increases sirt1 expression and prevents mitochondrial dysfunction and metabolic disorders in high-fat diet-induced obese mice. Am. J. Physiol. Endocrinol. Metab. 2012, 303, E1234-E1244.

81. Binder, E.; Bermudez-Silva, F.J.; Andre, C.; Elie, M.; Romero-Zerbo, S.Y.; Leste-Lasserre, T.; Belluomo, L.; Duchampt, A.; Clark, S.; Aubert, A.; et al. Leucine supplementation protects from insulin resistance by regulating adiposity levels. PLOS ONE 2013, 8, e74705.

82. Binder, E.; Bermudez-Silva, F.J.; Elie, M.; Leste-Lasserre, T.; Belluomo, I.; Clark, S.; Duchampt, A.; Mithieux, G.; Cota, D. Leucine supplementation modulates fuel substrates utilization and glucose metabolism in previously obese mice. Obesity (Silver Spring) 2014, 22, 713-720.

83. Pereira, M.G.; Baptista, I.L.; Carlassara, E.O.; Moriscot, A.S.; Aoki, M.S.; Miyabara, E.H. Leucine supplementation improves skeletal muscle regeneration after cryolesion in rats. PLOS ONE 2014, 9, e85283.

84. Murin, R.; Hamprecht, B. Metabolic and regulatory roles of leucine in neural cells. Neurochem. Res. 2008, 33, 279-284.

85. Sisk, C.L.; Nunez, A.A.; Thebert, M.M. Differential effects of electrolytic and chemical hypothalamic lesions on lh pulses in rats. Am. J. Physiol. 1988, 255, E583-E590.

86. Pizzi, W.J.; Barnhart, J.E.; Fanslow, D.J. Monosodium glutamate admlinistration to the newborn reduces reproductive ability in female and male mice. Science 1977, 196, 452-454.

87. Layman, D.K.; Walker, D.A. Potential importance of leucine in treatment of obesity and the metabolic syndrome. J. Nutr. 2006, 136, 319S-323S.

88. Donato, J., Jr.; Pedrosa, R.G.; Cruzat, V.F.; Pires, I.S.; Tirapegui, J. Effects of leucine supplementation on the body composition and protein status of rats submitted to food restriction. Nutrition 2006, 22, 520-527.

89. Fried, S.K.; Watford, M. Leucing weight with a futile cycle. Cell Metab. 2007, 6, 155-156.

90. Balage, M.; Dardevet, D. Long-term effects of leucine supplementation on body composition. Curr. Opin. Clin. Nutr. Metab. Care 2010, 13, 265-270.

91. Chakrabarti, P.; English, T.; Shi, J.; Smas, C.M.; Kandror, K.V. Mammalian target of rapamycin complex 1 suppresses lipolysis, stimulates lipogenesis, and promotes fat storage. Diabetes 2010, 59, 775-781.

92. Polak, P.; Cybulski, N.; Feige, J.N.; Auwerx, J.; Ruegg, M.A.; Hall, M.N. Adipose-specific knockout of raptor results in lean mice with enhanced mitochondrial respiration. Cell Metab. 2008, 8, 399-410.

93. Teodoro, G.F.; Vianna, D.; Torres-Leal, F.L.; Pantaleao, L.C.; Matos-Neto, E.M.; Donato, J., Jr.; Tirapegui, J. Leucine is essential for attenuating fetal growth restriction caused by a protein-restricted diet in rats. J. Nutr. 2012, 142, 924-930. 
94. El-Chaar, D.; Gagnon, A.; Sorisky, A. Inhibition of insulin signaling and adipogenesis by rapamycin: Effect on phosphorylation of p70 s6 kinase vs eif4e-bp1. Int. J. Obes. Relat. Metab. Disord. 2004, 28, 191-198.

95. Newgard, C.B.; An, J.; Bain, J.R.; Muehlbauer, M.J.; Stevens, R.D.; Lien, L.F.; Haqq, A.M.; Shah, S.H.; Arlotto, M.; Slentz, C.A.; et al. A branched-chain amino acid-related metabolic signature that differentiates obese and lean humans and contributes to insulin resistance. Cell Metab. 2009, 9, 311-326.

96. Newgard, C.B. Interplay between lipids and branched-chain amino acids in development of insulin resistance. Cell Metab. 2012, 15, 606-614.

97. Lynch, C.J.; Gern, B.; Lloyd, C.; Hutson, S.M.; Eicher, R.; Vary, T.C. Leucine in food mediates some of the postprandial rise in plasma leptin concentrations. Am. J. Physiol. Endocrinol. Metab. 2006, 291, E621-E630.

98. Pedroso, J.A.; Buonfiglio, D.C.; Cardinali, L.I.; Furigo, I.C.; Ramos-Lobo, A.M.; Tirapegui, J.; Elias, C.F.; Donato, J., Jr. Inactivation of socs3 in leptin receptor-expressing cells protects mice from diet-induced insulin resistance but does not prevent obesity. Mol. Metab. 2014, 3, 608-618.

99. She, P.; Van Horn, C.; Reid, T.; Hutson, S.M.; Cooney, R.N.; Lynch, C.J. Obesity-related elevations in plasma leucine are associated with alterations in enzymes involved in branchedchain amino acid metabolism. Am. J. Physiol. Endocrinol. Metab. 2007, 293, E1552-E1563.

100. Sans, M.D.; Tashiro, M.; Vogel, N.L.; Kimball, S.R.; D’Alecy, L.G.; Williams, J.A. Leucine activates pancreatic translational machinery in rats and mice through mtor independently of cck and insulin. J. Nutr. 2006, 136, 1792-1799.

101. Filiputti, E.; Rafacho, A.; Araujo, E.P.; Silveira, L.R.; Trevisan, A.; Batista, T.M.; Curi, R.; Velloso, L.A.; Quesada, I.; Boschero, A.C.; et al. Augmentation of insulin secretion by leucine supplementation in malnourished rats: Possible involvement of the phosphatidylinositol 3-phosphate kinase/mammalian target protein of rapamycin pathway. Metabolism 2010, 59, 635-644.

102. Van Loon, L.J.; Kruijshoop, M.; Verhagen, H.; Saris, W.H.; Wagenmakers, A.J. Ingestion of protein hydrolysate and amino acid-carbohydrate mixtures increases postexercise plasma insulin responses in men. J. Nutr. 2000, 130, 2508-2513.

103. Van Loon, L.J.; Saris, W.H.; Verhagen, H.; Wagenmakers, A.J. Plasma insulin responses after ingestion of different amino acid or protein mixtures with carbohydrate. Am. J. Clin. Nutr. 2000, 72, 96-105.

104. Rachdi, L.; Aiello, V.; Duvillie, B.; Scharfmann, R. L-leucine alters pancreatic beta-cell differentiation and function via the mtor signaling pathway. Diabetes 2012, 61, 409-417.

105. Pedrosa, R.G.; Donato, J.; Pires, I.S.; Tirapegui, J. Leucine supplementation favors liver protein status but does not reduce body fat in rats during 1 week of food restriction. Appl. Physiol. Nutr. Metab. 2010, 35, 180-183.

106. De Araujo, J.A., Jr.; Falavigna, G.; Rogero, M.M.; Pires, I.S.; Pedrosa, R.G.; Castro, I.A.; Donato, J., Jr.; Tirapegui, J. Effect of chronic supplementation with branched-chain amino acids on the performance and hepatic and muscle glycogen content in trained rats. Life Sci. 2006, 79, 1343-1348. 
107. Krebs, M.; Krssak, M.; Bernroider, E.; Anderwald, C.; Brehm, A.; Meyerspeer, M.; Nowotny, P.; Roth, E.; Waldhausl, W.; Roden, M. Mechanism of amino acid-induced skeletal muscle insulin resistance in humans. Diabetes 2002, 51, 599-605.

108. Shah, O.J.; Wang, Z.; Hunter, T. Inappropriate activation of the tsc/rheb/mtor/s6k cassette induces irs1/2 depletion, insulin resistance, and cell survival deficiencies. Curr. Biol. 2004, 14, 1650-1656.

109. Ueno, M.; Carvalheira, J.B.; Tambascia, R.C.; Bezerra, R.M.; Amaral, M.E.; Carneiro, E.M.; Folli, F.; Franchini, K.G.; Saad, M.J. Regulation of insulin signalling by hyperinsulinaemia: Role of irs-1/2 serine phosphorylation and the mtor/p70 s6k pathway. Diabetologia 2005, 48, 506-518.

110. Giraud, J.; Leshan, R.; Lee, Y.H.; White, M.F. Nutrient-dependent and insulin-stimulated phosphorylation of insulin receptor substrate-1 on serine 302 correlates with increased insulin signaling. J. Biol. Chem. 2004, 279, 3447-3454.

111. Zhang, J.; Gao, Z.; Yin, J.; Quon, M.J.; Ye, J. S6k directly phosphorylates irs-1 on ser-270 to promote insulin resistance in response to tnf-(alpha) signaling through ikk2. J. Biol. Chem. 2008, 283, 35375-35382.

112. Hotamisligil, G.S.; Peraldi, P.; Budavari, A.; Ellis, R.; White, M.F.; Spiegelman, B.M. Irs-1-mediated inhibition of insulin receptor tyrosine kinase activity in tnf-alpha- and obesity-induced insulin resistance. Science 1996, 271, 665-668.

113. Hirosumi, J.; Tuncman, G.; Chang, L.; Gorgun, C.Z.; Uysal, K.T.; Maeda, K.; Karin, M.; Hotamisligil, G.S. A central role for jnk in obesity and insulin resistance. Nature 2002, 420, 333-336.

114. Bomfim, T.R.; Forny-Germano, L.; Sathler, L.B.; Brito-Moreira, J.; Houzel, J.C.; Decker, H.; Silverman, M.A.; Kazi, H.; Melo, H.M.; McClean, P.L.; et al. An anti-diabetes agent protects the mouse brain from defective insulin signaling caused by alzheimer's disease- associated abeta oligomers. J. Clin. Investig. 2012, 122, 1339-1353.

115. Zemel, M.B.; Bruckbauer, A. Effects of a leucine and pyridoxine-containing nutraceutical on fat oxidation, and oxidative and inflammatory stress in overweight and obese subjects. Nutrients 2012, 4, 529-541.

116. Donato, J., Jr. The central nervous system as a promising target to treat diabetes mellitus. Curr. Top. Med. Chem. 2012, 12, 2070-2081.

117. Pelleymounter, M.A.; Cullen, M.J.; Baker, M.B.; Hecht, R.; Winters, D.; Boone, T.; Collins, F. Effects of the obese gene product on body weight regulation in ob/ob mice. Science 1995, 269, 540-543.

118. Berglund, E.D.; Vianna, C.R.; Donato, J., Jr.; Kim, M.H.; Chuang, J.C.; Lee, C.E.; Lauzon, D.A.; Lin, P.; Brule, L.J.; Scott, M.M.; et al. Direct leptin action on pomc neurons regulates glucose homeostasis and hepatic insulin sensitivity in mice. J. Clin. Investig. 2012, 122, 1000-1009.

119. Turnbaugh, P.J.; Ley, R.E.; Mahowald, M.A.; Magrini, V.; Mardis, E.R.; Gordon, J.I. An obesity-associated gut microbiome with increased capacity for energy harvest. Nature 2006, 444, 1027-1031.

120. Murphy, K.G.; Bloom, S.R. Gut hormones and the regulation of energy homeostasis. Nature 2006, 444, 854-859. 
121. Chen, Q.; Reimer, R.A. Dairy protein and leucine alter glp-1 release and mrna of genes involved in intestinal lipid metabolism in vitro. Nutrition 2009, 25, 340-349.

122. Xu, G.; Stoffers, D.A.; Habener, J.F.; Bonner-Weir, S. Exendin-4 stimulates both beta-cell replication and neogenesis, resulting in increased beta-cell mass and improved glucose tolerance in diabetic rats. Diabetes 1999, 48, 2270-2276.

123. D’Alessio, D.A.; Kahn, S.E.; Leusner, C.R.; Ensinck, J.W. Glucagon-like peptide 1 enhances glucose tolerance both by stimulation of insulin release and by increasing insulin-independent glucose disposal. J. Clin. Investig. 1994, 93, 2263-2266.

124. Layman, D.K. The role of leucine in weight loss diets and glucose homeostasis. J. Nutr. 2003, 133, 261S-267S.

125. Layman, D.K.; Boileau, R.A.; Erickson, D.J.; Painter, J.E.; Shiue, H.; Sather, C.; Christou, D.D. A reduced ratio of dietary carbohydrate to protein improves body composition and blood lipid profiles during weight loss in adult women. J. Nutr. 2003, 133, 411-417.

(C) 2015 by the authors; licensee MDPI, Basel, Switzerland. This article is an open access article distributed under the terms and conditions of the Creative Commons Attribution license (http://creativecommons.org/licenses/by/4.0/). 